\title{
The church of Cristo Re in Cagliari, 1952-1963, G. Genta and S. Panzarasa: tradition and modernity in the architecture of the central sacred space
}

\author{
Andrés Martínez-Medina ${ }^{10000-0002-5309-9310]}$, Vincenzo Bagnolo ${ }^{20000-0002-7297-9196]}$, and \\ Andrea Pirinu ${ }^{20000-0001-8569-2605] ~}$ \\ ${ }^{1}$ DEGCP, Universidad de Alicante, Alicante, 36930, SPAIN \\ 2 DICAAR, Università degli Studi di Cagliari, Cagliari, 09123, ITALY \\ andresm.medina@ua.es; vbagnolo@unica.it; apirinu@unica.it
}

\begin{abstract}
The church of Cristo Re (Fig. 1) in Cagliari, 1952-1963, by G. Genta and S. Panzarasa, is a centralized temple erected for the titular congregation of nuns that would also serve for the religious services of the neighborhood of the urban expansion experienced in the Monte Urpino area. It is a work with some novelties of the modern movement compounding the revisions of the middle of the century, but is rooted in the Catholic typologies of the hexagonal plan and reinterprets the symbolism of the roof as a star in the sky, for which it adopts baroque perspective strategies. Born as the 'Sacro Cuore' church, the project was developed by young graduates in Rome in 1946 who were recommended by A. Libera, who would imbue them in the management of the golden proportions. It is a hybrid building which in fact modernizes languages, forms, liturgy, structure and materials thanks to the emerging organic architecture, and at the same time conscious of tradition: centrality of the sacred space, vertical axis to the cosmos and demanding geometry, as well as its canonical orientation. In short: a modern diaphanous sacred space enclosed in a somewhat expressionist volume, but, in essence, Classical and Mediterranean.
\end{abstract}

Keywords: Cristo Re Church Cagliari, Modern Sacred Space, Modern and Organic Religious Architecture, Centralised Plant Typology, Hexagonal Plans.

"The universe (which others call the Library) is made up of an indefinite, and perhaps infinite, number of hexagonal galleries, with vast ventilation shafts in the middle, encircled by very low railings. From any hexagon you can see the upper and lower floors endlessly."

José Luis Borges. The Library of Babel, 1941 


\section{Three typologies: longitudinal, central and hybrid}

Within the long-standing Christian tradition, the symbolism of its temples usually alludes to the cross of Christ or the celestial vault, which is materialized in two basic architectural types. It is about two typological families organised around a main axis: horizontal of ritual path or perpendicular of spiritual ascent; both types have been endowed with an important verticality identified with spirituality.

The first family would be present in the churches with a longitudinal nave plan (basilica or Latin cross) and the second in those with a central plan, whose geometry, between polygonal and circular, is covered with a dome. Oblong spaces are more functional and accommodate more faithful than central ones, which show a greater symbolic load: from the Holy Scriptures, where the tracing of a circle to create the heavens is already mentioned, to the magical implications that were adhered to in the 20th century (Gil 1999, pp. 66-67). However, for centuries, it is common for these sacred spaces, in the Catholic sphere, to present hybrid solutions that combine both axes and, perhaps, the church of the Gesú in Rome, is the model in response to a change in the liturgy, as admitted by Cardinal Lercaro in 1956 (Gherardi et Alt. 1956, p. 17).

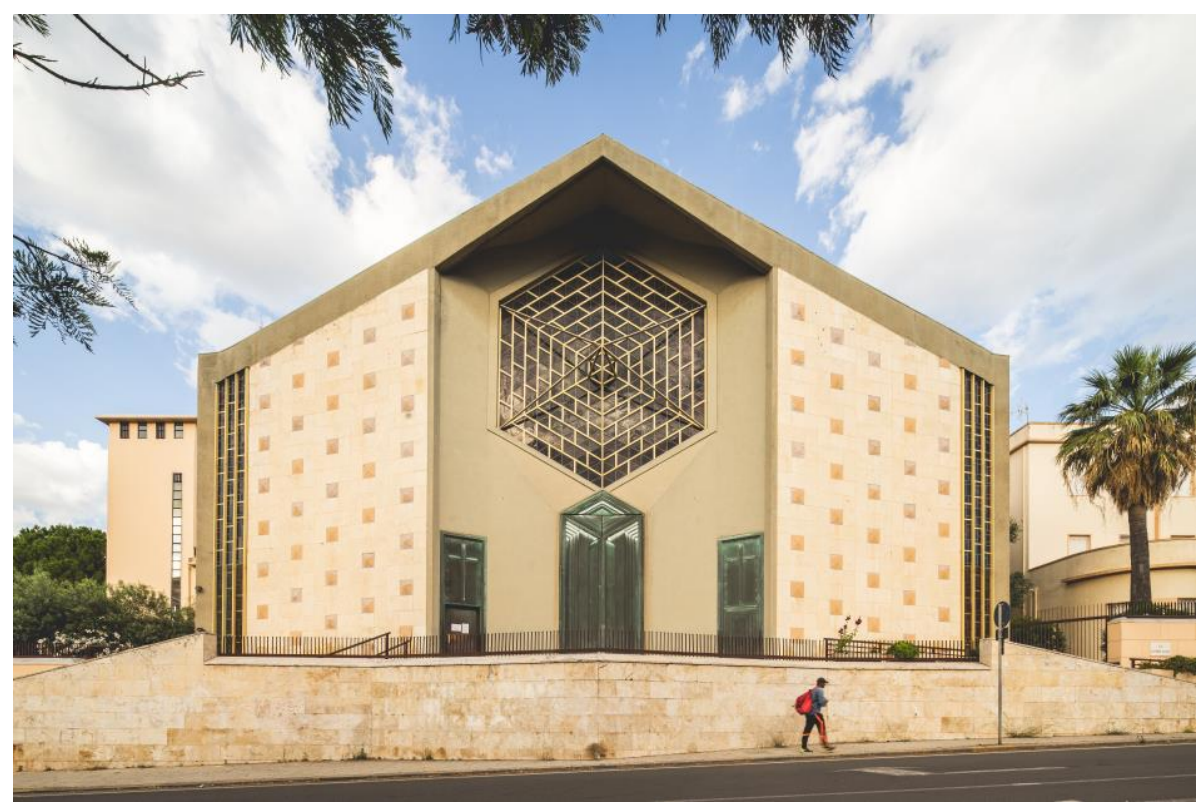

Fig. 1. Cristo Re church, Cagliari, 1953-1962, G. Genta \& S. Panzarasa (N. Paba 2020).

A good example of the slow evolution of Christian temples and, in particular of Catholic ones, is the full validity of these three genealogies in the first half of the 20th century. A review of the projects and works produced in Italy until the outbreak of World War II (Meduri 2016) shows the use of these three typologies - longitudinal, central and hybrid - with a predominance of elongated plans, apart from the 'reviv- 
als' or the irruption of other formalisms alluding to interwar modernity (aimed at geometric reduction and the suppression of past styles), as well as the use of exposed concrete inside the naves; an example is the 1934 church of Villagio Falk in Milan. In fact, both the critics of the period (the case of G. Bellonci) and the architecture magazines of this period (Arte Sacra and Rasegna di Architettura, founded in 1929) insist on considering that the Catholic temples erected since 1800 had contributed very little: neither had they renewed their liturgical functionality, nor had they maintained the traditions of canonical orientation, of the mandatory preceding square and of the adequate urban environment (Meduri 2016, pp. 153-177).

\section{The renewal of architectural type in post-World War II Italy}

Things, however, changed in the second post-war period: the interest of the Curia to update the architecture finds the active initiative of professional groups. In September 1955, 1st National Congress of Sacred Architecture of Italy, promoted by the Primate of Bologna, took place. This conclave brings together in the city the experts involved in the modernisation of religious architecture, who provide criteria, projects and works, taking stock of the progress made in a decade of reconstruction of the country (Gherardi et Alt. 1956). Two exhibitions gravitate around the event: one on clothing and works of art, and the other on religious architecture.

Two architects with a consolidated trajectory, Ludovico Quaroni and Giovanni Michelucci, are in charge of the main presentations that deal with the church-city and art-space binomials, paying special attention to the new peripheral neighborhoods. In his speech, Quaroni affirms that not always the push towards a deeper sense of sacred building came from the clergy, which indeed sometimes showed the impediments and limits deriving from concern about changes in passive respect for the so-called "tradition" (Gherardi et Alt. 1956, p. 31), inviting reflection on the spiritual values of architecture and life as a prologue to the renewal of the sacred space. In this forum architecture is defined as "the art of organizing spaces" (Gherardi et Alt. 1956, p. 56), somewhat in the shadow of B. Zevi.

The congress and the architecture exhibition are collected in a catalogue in 1956 that compiles almost eighty examples between projects (competitions, proposals and models) and works (in progress or finished). The universal vocation of the event is evidenced by both the adhesions of foreign associations and professionals, as well as the publishing of an edition in four languages of the book itself; this internationalisation seems to be shared by the 'Gothic North' and the 'Mediterranean South' - the taxonomy of Pugin (Johnson 2008, p. 160)—, since the ecumenical environment that runs through Europe after the armed conflicts encourages experimentation both in Protestant as well as Catholic temples; other selections and other judgments would unfold in the following decade in a multitude of books and atlases of religious architecture (Pichard 1960; Fernández 1963; Kiddler 1964). In the Italian catalogue, where there is a wide range of solutions, the shift towards modernity is noted, a shift that shows the exemplification of the "stages", clarifying structuralism, functionalism, 
organic architecture and anti-rational, etc.: in a word, the "categories" of the new architectural practice (Gherardi et Alt. 1956, p. 138).

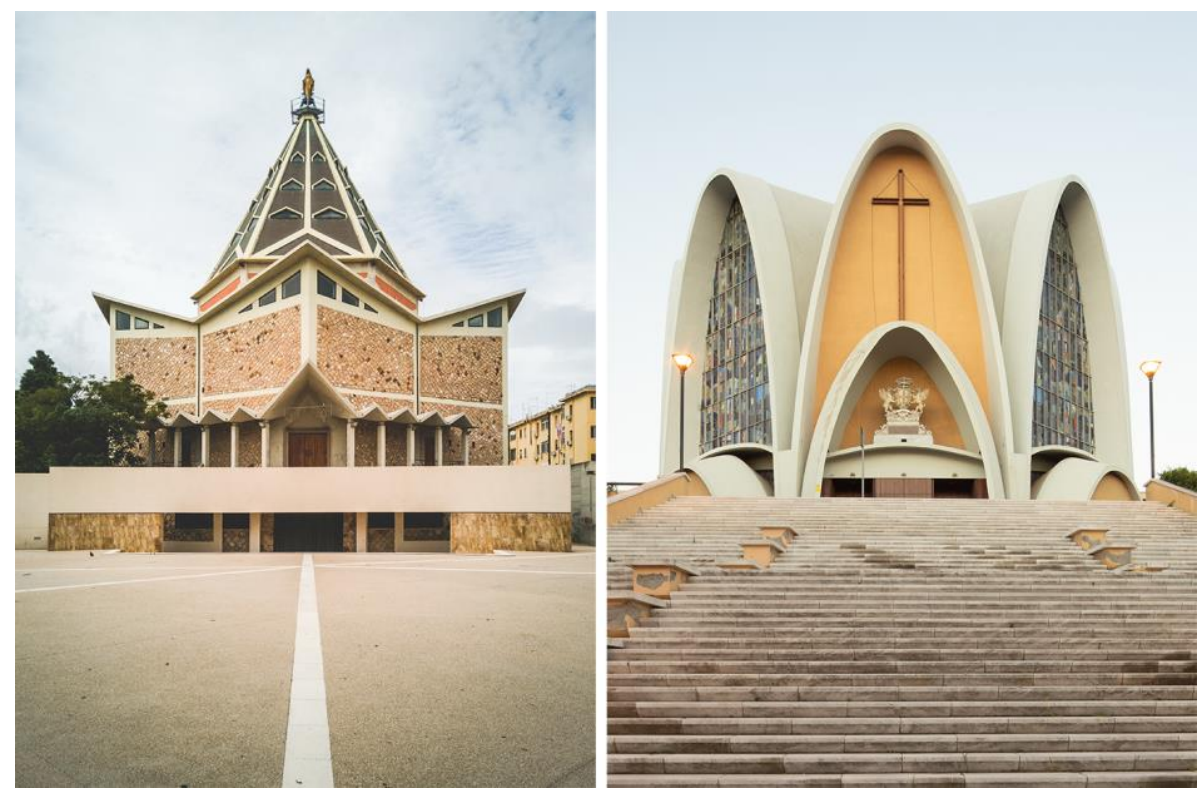

Fig. 2. (a): Medaglia Miracolosa parish, Cagliari, 1953-1969, Angelo Verri. (b): Santi Giorgio e Caterina parish, Cagliari, 1957-1969, Francesco Giachetti \& Marco Piloni (N. Paba 2020).

The character of this exhibition was more documentary than critical, with varying degrees of quality of the works that exhibited a great overview, and the innovations, as well as the permanence, were evident, especially due to the irruption of reinforced concrete with its unlimited structurally resistant alternatives, plastic nature and textures. We should add the disappearance of classicist languages, replaced by all kinds of abstract designs. However, given that there had been no changes in the liturgy, the exposed structures and the disappearance of the historic domes would be the protagonist, with some exceptions - as in the case of the reconstruction of the church of San Domenico in Cagliari (Sanna 2009)_, the two visual and compositional features that stand out the most in the sample, as well as the constant verticality in the main nave. An indication of the changes in the professional landscape would be that the two projects are signed by two women architects: Claudia Agostini and Marisa Forlani.

\section{Sacral geometries: centralized spaces and hexagonal plans}

An analysis of the typologies present in this exhibition shows that some traditions remain and, thus, the longitudinal type is the majority in almost $80 \%$ of the projects, while the remaining $20 \%$ are distributed equally between central and hybrid types. Regarding the longitudinal solutions (of one or three naves) it should be noted that 
among them there appear, with considerable success, proposals in which the temple shows a stretched hexagon perimeter and that the study of G. Ponti would 'perfect' years later in the church of San Francesco al Fopponino in Milan. Regarding hybrids, the church of Santa Maria Maggiore in Francavila al Mare (1948-59) by Quaroni, should be mentioned, with an oblong octagon plan surrounded by a low ambulatory, because "it has been considered a manifesto of the linguistic revisionism of postwar Italian architecture" (Della Longa 2007, p. 109).

The centralised types are represented with eight examples (all in project form) of which four show regular polygon floors (4, 6, 8 and 12 sides) and four are circular; of the round floor type two would be built: the church Santa Maria Nascente in Milan (1947-55, Magistretti and Tedeschi) and that of the Cuore Immacolato di Maria in Bologna (1955-60, Vaccaro and Nervi). Again, certain constants persist that confirm the figures of the circle and the octagon as the most recurrent for centralised temples. These sacral spaces are no longer covered with domes of spherical form, but, in many cases, with roofs of folded planes. The centralised plans, therefore, reaffirm their exceptionality and singularity as a liturgical solution and only one of the projects in the sample uses the regular hexagon in the genesis of its floor plan: the Gesú Divino Operaio church in Triestre (1955, Lucci), finally not built.

The centralised floor plans are of interest because they contextualise the three churches of this type erected in Cagliari from 1950 onwards: the church of Cristo Re (1952-63) (Fig. 1) and the Medaglia Miracolosa (1953-69) (Fig. 2a), both with a hexagonal plan and pre-dating the designs pertaining to the Bologna exhibition, as well as the Santi Giorgio e Caterina (1957-67) (Fig. 2b), with an octagonal perimeter, inspired by that of St. Engelbert in Cologne (1928-32, Böhm). But, if the centralised plans are not widely used, within this arrangement, the hexagonal ones are usually the exception, both because of their demanding geometry (angles at $60^{\circ}$, access position, execution of the structure and intersections), and because of their multiple religious symbolisms, derived from the equilateral triangle at its base, and by its echo in nature. In fact, the two churches with a hexagonal plan in Cagliari are articulated in a different way: while the temple Medaglia Miracolosa raises the access in a vertex, creating an axis of symmetry that joins two opposite corners, the temple Cristo Re church does it to half of one side, generating a main axis between the midpoints of the opposite edges, more in keeping with tradition.

Obviously, going back in history, religious architectures conceived from a regular hexagon are discovered already in the Ancient and Medieval ages. This type would be codified in the Renaissance treatise: S. Serlio himself, in his Libri III and $V(1551)$, already draws the Tempio hessagono (Fig. 3a) and G.B. Montano also reproduces hexagonal plants in Scielta di vari tempietti antichi (1624); in fact, from this time drawings of some projects such as the one by Pianta di Chiesa sesagona (Roman section, 1600-1640) are preserved (Fig. 3b). During the Baroque century some churches with this arrangement were erected, such as the church of Santa Maria del Quartiere in Parma (1604-19). But the best-known temple with the greatest impact on the Catholic architectural tradition is Sant'Ivo alla Sapienza in Rome (1643-62). 


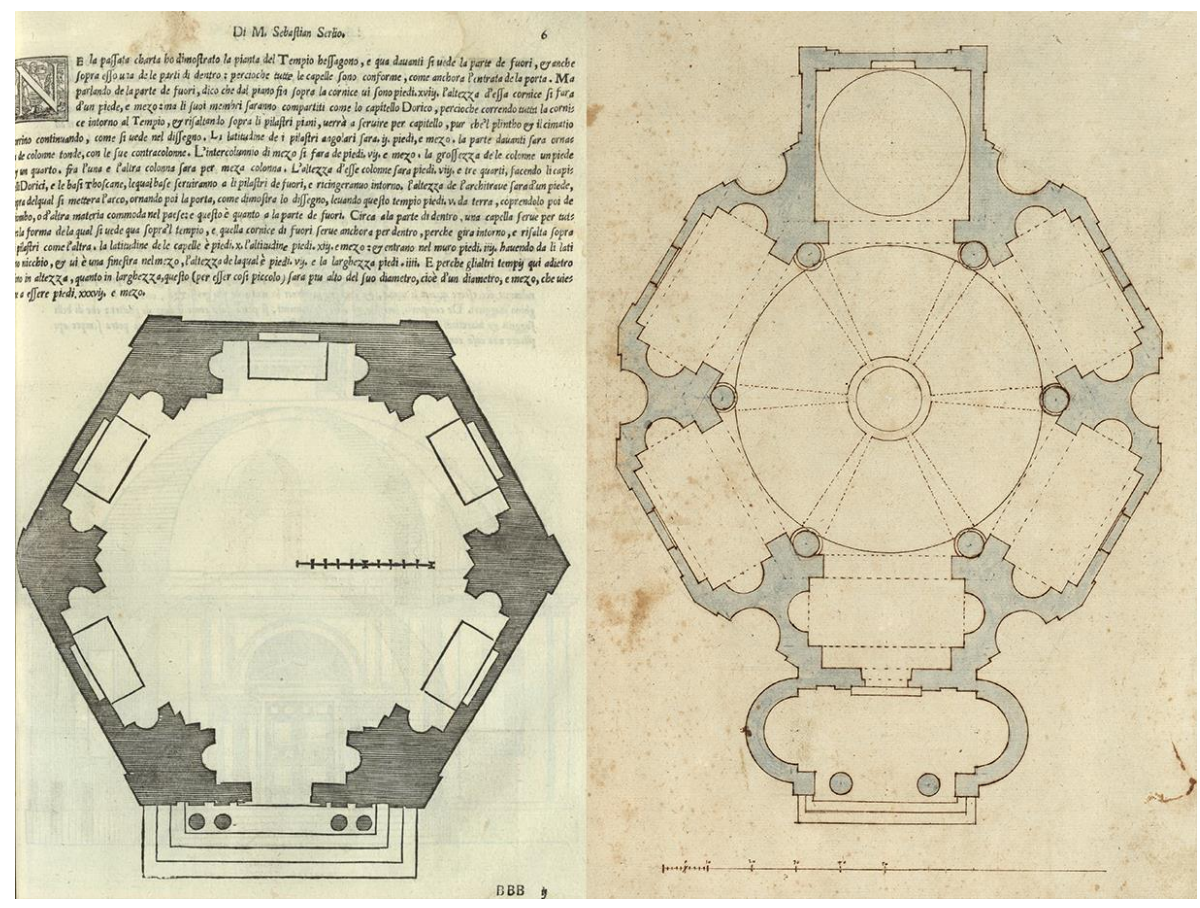

Fig. 3. (a): Tempio hessagono, S. Serlio, Libro $V, 1551$ (public domain).

(b): Pianta Chiesa sesagona, 1600-1640 (Gabineto).

\section{Between the 'Sacro Cuore' and 'Cristo Re' churches: sacred space with baroque evocations}

The church of Cristo Re in Cagliari was commissioned by the Mother of the congregation of this name, Bruna Maxia, on July 19, 1952 to the couple of young architects Giuliana Genta (1922-2005) and Silvano Panzarasa, both graduated in 1946 from the University of Rome in the Faculty of Architecture. As of 1950, Adalberto Libera was in Cagliari directing case economiche per lavoratori in via Pessina (city-garden) which was followed by the Padiglione espositivo Casmez (Loddo 2001). As the tandem admits, Libera himself mentioned their names to the Mother Superior of the convent of the sisters of Figlie di Cristo Re in Cagliari (ACS 1983), whom they had met at the INA-Casa offices in Rome where they had started working in 1950 under the guidance of A. Foschini (Aa.Vv. 2001, p. 222).

It would not be strange that G. Genta and S. Panzarasa, faced with the challenge of a temple within a few years of being titled, took the churches of F. Borromini -genial architect wayward, but classical - as a reference, both for his teaching in the expansion of space, as for its unusual geometric and constructive resources. The use in the temple of Cristo $\mathrm{Re}$ of a network of equilateral triangles that generate the hexagon (triangles that are in the section of the columns and in the sketches of the fresco planned for the inferior surface of the church stellar covering) could be inspired by 
the Baroque master. It should be noted that the first name of this church was that of the 'Sacro Cuore' (ACS 1952) (organ that invokes the center and whose heartbeat expands life, here: space), which is designed from a hexagon -9 meters on a side and bounded by 6 free-standing columns of 3 faces each - whose void explodes until it reaches the outer rectangular perimeter: a mathematical series $(3,6,12)$ is allied with another geometric one (triangle, hexagon, star). The diaphanous nave thus defined is, significantly, oriented to the east thanks to the provisions of the Master Plan that allowed the temple to be placed in front of a square (ACS 1952) (Fig. 4a).

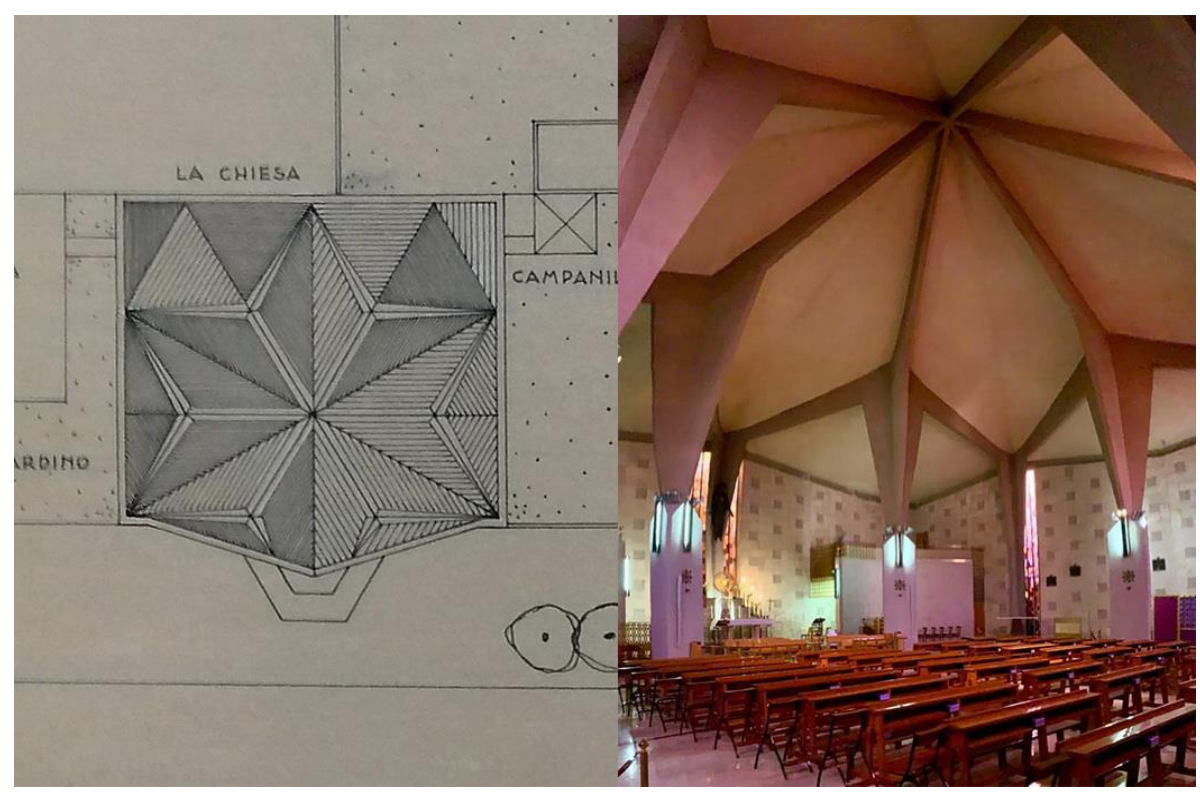

Fig. 4. (a): Location plan of Cristo Re church with star-shaped roof and free-standing bell tower (ACS, Archivio Giuliana Genta, 1952. Concession n.1632 / 2021 by permission of the Italian Ministry for Cultural Heritage and Activities. Reproduction or duplication in any form or by any means is prohibited). (b): interior of the sacred space (Authors 2020).

Although the interior of the church is read in a modern key of diaphanous space and its dome, faceted, is closer to a Star of David molded in volume (Fig. 4b), the reverberation of Sant'Ivo alla Sapienza, with its hexagonal space expanded with the side chapels and the dome of six segments is coincident. Not so on the flooring since, while Borromini uses six-sided polygonal slabs (but with $45^{\circ}$ angles), Genta and Panzarasa deploy rhomboidal pieces of beige marble to cover each of the six triangles of the church covering that are reflected on the floor, figures that are sealed by a garnet marble border; both marbles, like the stone of the walls, come from the quarries of Sardinia.

Another indication of this proximity to the solutions of the Lombard master would be the two preparatory drawings to paint the ceiling of the church which, moulded by the triangular folds, is designed with a mesh of concentric circumferences (whose 
diameters shorten their distances towards the center), in whose rings borders of rhombuses and triangles are inserted in a range of colors from yellow to red that evokes the 'Day' (Fig. 5a) or borders with a string of small squares containing a cross each in a range from blue to violet that recalls the 'Night' (Fig. 5b). This chromatic gradient and the decrease in the figures as they approach the top of the space, visually increase the height of the nave, which it's controlled by the golden proportions; we have recreated the atmosphere of both solutions with two photomontages (Fig. 6).
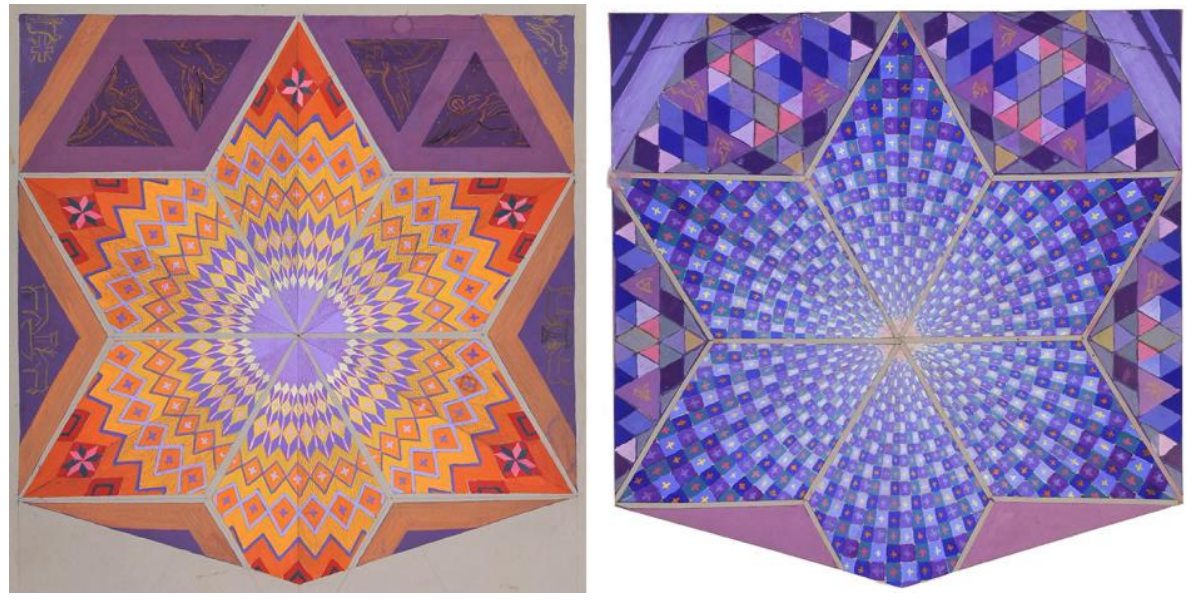

Fig. 5. Geometric designs for the dome of Cristo Re. (a): To diamonds with orange tones, Day. (b): To blue squares, Night; Genta \& Panzarasa (ca. 1955-57, ACS, Archivio Giuliana Genta. Concession n.1632 / 2021 by permission of the Italian Ministry for Cultural Heritage and Activities. Reproduction or duplication in any form or by any means is prohibited).

This effect of resorting to a pattern of regular polygons, whose dimensions are shortened with depth, was already used by Borromini in San Carlo alle Quattro Fontane in Rome: the set of caissons (octagonal, hexagonal and cross) raise the height of the tiny sacral interior. Genta and Panzarasa, instead of opting for a figurative trompe l'oeil that opens the vault to the sky (as in Sant'Ignazio, Rome), they choose these crowns to make the ceiling a painted sky in order to enhance the ascending effect (Tagliacollo et Alt. 2005, p. 40) which, however, would not be executed. It is worth remembering the ancient meaning of these allegories according to the expert Mircea Eliade described in 1957: the simple contemplation of the celestial vault is enough to trigger a religious experience. The sky is revealed as infinite, as transcendent. (Eliade 2015, p. 88) that, here, the designers prefer to represent, not in a figurative pictorial way, but by printing an architectural character through geometry. It seems clear that the architects, conscious, wanted to bring the firmament to the underside of the roof which revisits the idea of a ribbed vault in a modern key (Tagliacollo et Alt. 2005, p. 40), a rather ancient symbolism, for which they resorted to geometries (Star of King David), shapes (concentric circumferences) and perspective effects (color gradient and size reduction) as project strategies. Other architects, such as Paolo Portoghese (1965, 
Sacra Famiglia a Fratte church), would also experiment with a symbolism rooted in history, within the heritage of the Baroque tradition (Longhi, Tosco 2010, p. 59).
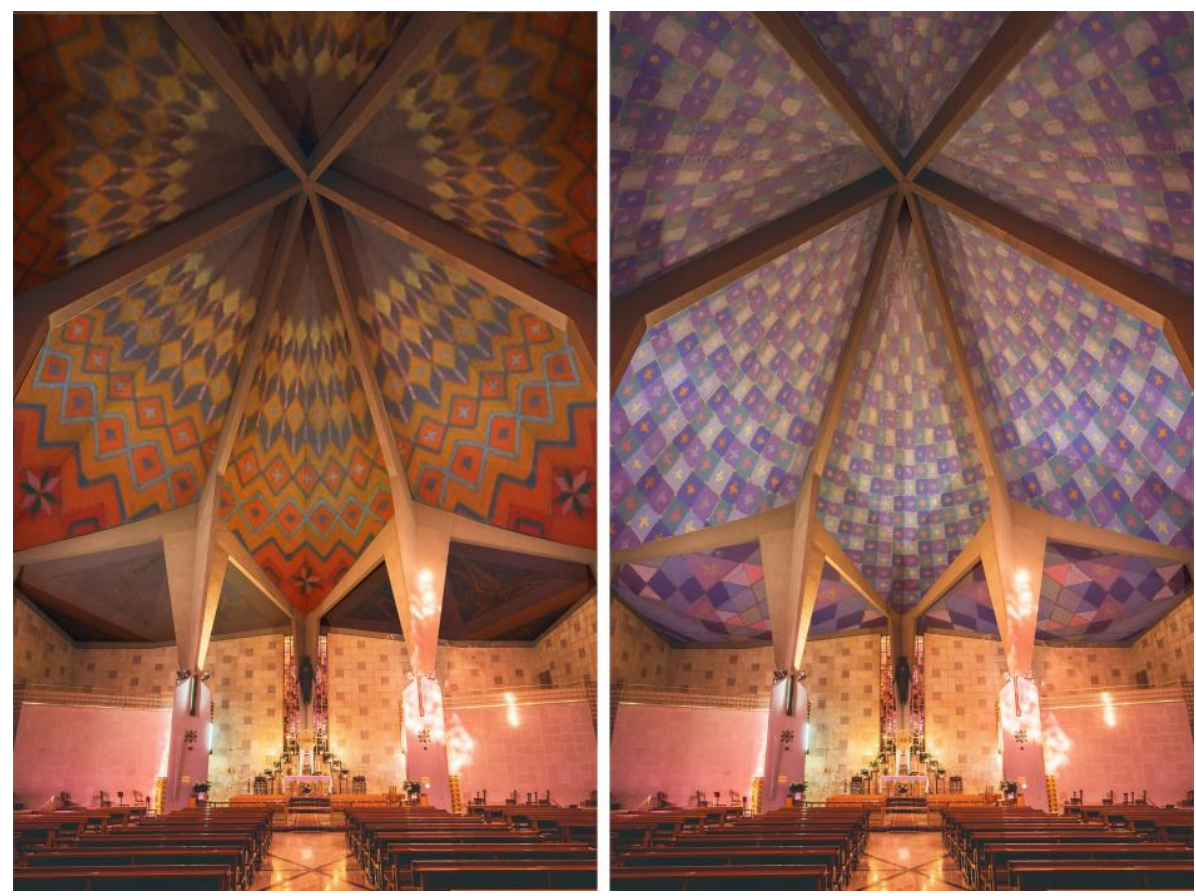

Fig. 6. Photomontages on the current church of the two designs for the sky of the dome: Day (left) and Night (right) (N. Paba 2020).

Obviously, all this was combined with a modern poetics that was based on the hexagon and the isometric mesh that it generates, but that accuses other contemporary influences such as the use of regulatory golden tracings and the arrival of organic architecture in Europe right in the middle century. In fact, the mother superior herself was concerned if the church would adopt an excessive modern spirit, since it and the congregation preferred ancient architectural lines adapted to modern architecture (ACS 1983). It was the nuns themselves who opted for a modern design which reinterpreted Baroque traditions: they strongly endorsed their decision despite the perplexities and contrary opinions of the benefactors, firmly supporting the ideas of the two architects also in view of the hesitations of the highest ranks of the church called to judge (ACS 1983). Thus, the languages of the modern movement were introduced, in many cases, through the filter of cultured tradition. There is no doubt that, in the church of Cristo Re, its conception and formalisation is modern, but its essence is classical. 


\section{Urban expansions, regulatory paths and organic architecture}

Before 1945, the architectures related to the orthodoxy of the modern movement were not dominant, although it had already established itself in a new Academy; even fewer were the examples if the inventory was limited to religious works, although there was serious progress in sacred types in the interwar period in Central Europe, both in Protestant and Catholic cases (Gil, 1999) ${ }^{1}$. But this panorama would vary after World War II, since the reconstruction programs of the old continent - material and spiritual-, in addition to recovering the damaged churches, included the parishes as a vital endowment of the brand-new neighbourhoods and as milestones of social identity of the new migrant vicinities.

All of Europe would promote new churches in each new urban settlement. And Italy would not be an exception to this situation (Longhi 2017, p. 15) which, driven by congresses on purpose and by the publication of these works in the professional mass media - the monographic numbers multiplied throughout Europe as in the case of L'Architecture d'aujourd'hui (France), Domus (Italy), Arquitectura (Spain), etc.- had the approval of the ecclesiastical and civil powers, who used these platforms to build a new architectural viewpoint — updated and renewed - with which to equip the settlements peripherals. All of this can be read as a propaganda campaign for Christian values that uses the language of advertising. However, sacred architecture, in itself, did not undertake any social improvement, something that the hygienist modern movement was supposed to do because of its scientific principles.

The urban expansion that took place between 1945 and 1975, an example of the 'Italian economic boom' of the time, was articulated under the principles of functionalist urbanism of the CIAM which, in the case of Cagliari, multiplied its habitable surface through the execution of neighbourhoods of public and private promotion. In these three decades, some twenty new temples and parishes were built in the new settlements of the metropolitan area (Loddo 1996; Piseddu 2000), of which a quarter were centralized temples (Fig. 7). In all these urban areas of open blocks created in Italy, the churches (visually prominent) would occupy a relevant urban place and would be the object of special attention in all their demands in journals founded for their debate and resolution (Bettazi et Alt. 2004); they would also be a field of exploration for the spatial, aesthetic, functional and structural concepts of modern architecture, the bearer of a certain abstract art. Faced with the fact that these religious architectures were the object of so much media support between 1945 and 1975, their almost disappearance in the media from that date is surprising as much as their lack of contribution to the critical architectural and urban debate of the post-war period since neither they are considered a theme or typology of relief (Conforto et Alt. 1977).

\footnotetext{
${ }^{1}$ We cannot present here all the proposals drawn, designed or built during this period, but we will mention some professionals who participated in this renovation of religious architecture such as: Perret (France), Mosser (Switzerland), Schwarzs, Böhm and Barting (Germany), Oud (Holland), Asplund and Lewerentz (Sweden) and Aalto (Finland), among others.
} 


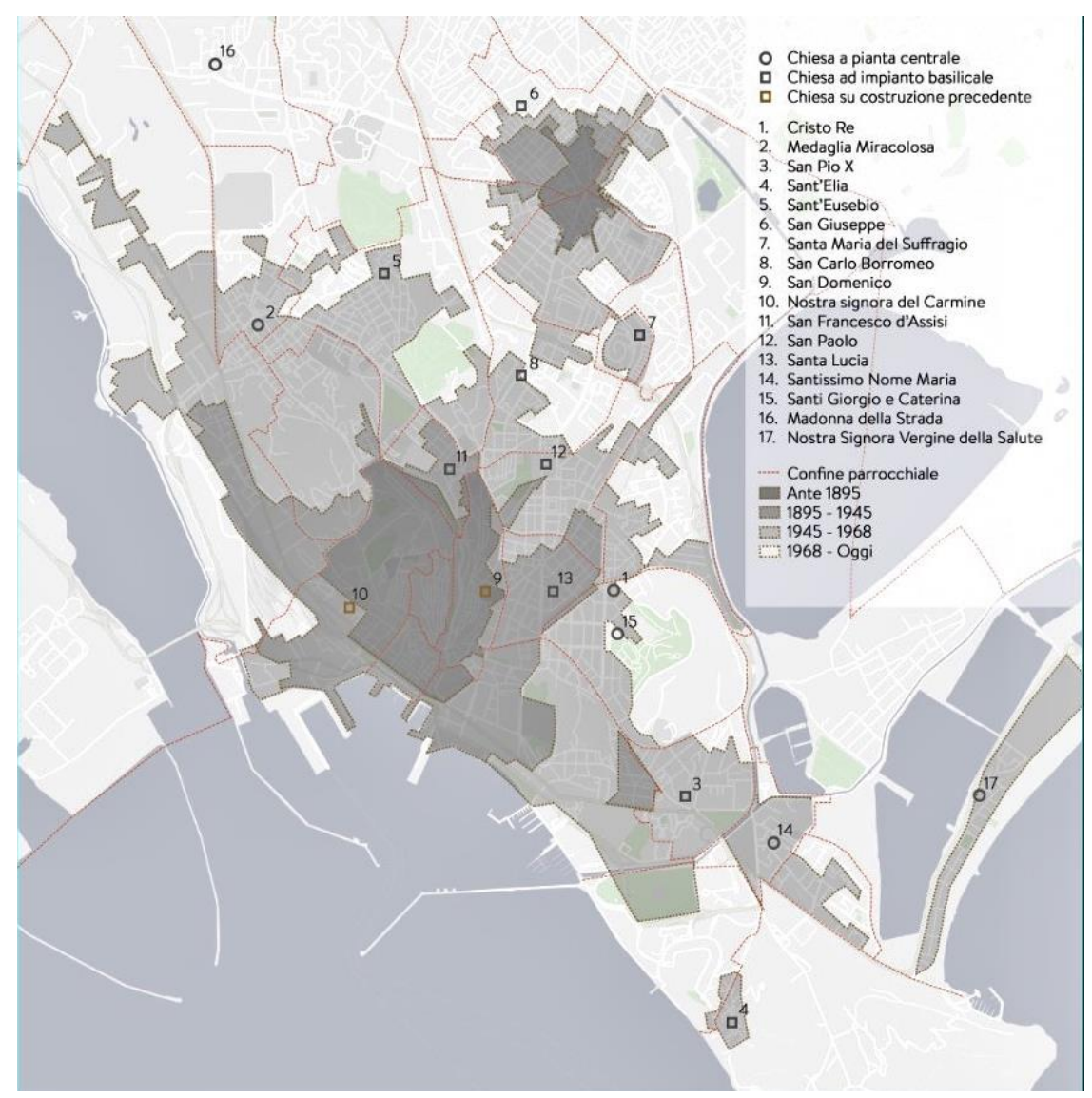

Fig. 7. Map of the City of Cagliari with an indication of the neighborhoods of urban expansion (1945-1975) with marking of their churches (N. Paba 2020).

However, orthodox architecture had spread a tabula rasa from the past and, consequently, all modern architecture had to start from scratch. The break with history was worth as a slogan, but the reality was more complex, apart from media manipulations and operational criticism. Two themes of interest would be revealed on the architectural horizon after World War II: some leaders of the movement used project mechanisms typical of the Renaissance and the aesthetics of the modern movement abstract, cold and objective - was excessively intransigent and had purposely excluded characters fundamentals - as in the case of Wright and Schindler, who relied on the tradition- branded as heterodox, if not heretics, since the new elite sanctioned in 1932 by MoMA (Hitchock, Johnson 1984).

Le Corbusier, in his book Vers une architecture, of 1923, included the golden proportions of his villas. The Swiss master was not bothered by the fact that a decade later, in 1933, E. Kauffman suggested a thread that linked him to the principle of architectural autonomy of the Enlightenment in the book: Von Ledoux bis Le Corbusier... A thread that seemed to have older origins according to R. Wittkower in his 
1949: Architectural principles in the Age of Humanism, and that his disciple C. Rowe confirmed with his impressive of 1947: "The mathematics of the ideal villa..." and the following one from 1950: "Mannerism and modern architecture". In this way, the "direct relationship between the classical past and the work of the masters of the 20th century" (Vidler 2011, p. 87) and that the specificity of architecture did not lie in the surfaces, but in the creation of new spaces. The diagrammatic representation of the floors of the villas (understood as tiny temples) turned the compositional systems into a timeless mechanism. That the teachers resorted to the golden proportions and antecedents in the past was assumed as a cultism and a guarantee of harmony: Le Corbusier, Mies, Terragni or Libera recorded this practice.

No less impressive was the publication of Storia dell'architettura moderna (History of Modern Architecture), in 1950, by B. Zevi. It was the first book to address modern production using the term History; it had been written during his exile and stay at Harvard University (Vidler 2011, pp. 32-33). The speech expanded its registers with a wide range of North American works, among whose authors Wright stood out as the inventor of organic architecture, a more material and less abstract architecture, based on less radical geometries than those of the Neue Sachlichkeit. Zevi had previously published Verso un'architettura organica in 1945 (Towards an Organic Architecture), Frank Lloyd Wright in 1947 and Saper vedere l'architettura in 1948 (Architecture As Space: How to Look at Architecture), a book that revisited architecture from its origins to argue that its objective was the creation of spaces. During these years, Wright had designed various sacred places in which the orthogonal grid had been replaced by more flexible ones such as circular or triangular ones and had used it in the Stell Cathedral (1926) and the First Unitarian Society of Madison (1949). The interest in organic architecture and that of Wright would make the front page of magazines and exhibitions, such as the one held in Florence in 1951 at the same time that he was awarded doctor honoris causa in Venice.

Giuliana Genta and Silvano Panzarasa, who studied in the eternal city, had among their teachers Piacentini, Fasolo, Quaroni, who at the time was an assistant, and Nervi, who made the first experiments on structures with plastic models (Capolino et Alt. 2008, p. 32). Giuliana Genta, at the end of her studies, participated at the conferences on organic architecture promoted by Bruno Zevi and was hired as an architect at INACasa (Capolino et Alt. 2008, p. 32). And at INA-Casa, she met Libera with whom she would work on various residential projects (Aa. Vv. 2001, p. 222). From the master she learned to resort to golden proportions as a method for designing architecture (Capolino et Alt. 2008, p. 32), thus becoming aware of his method of detailed analysis of each element (Aa.Vv. 2001, p. 222).

The application of the regulatory proportions in the Cristo Re church obeys, both the Italian tradition itself, and the neighbourhood with Libera, who closely followed this work. In fact, the temple is articulated from a central hexagon, a regular figure that, when raised from the ground, also governs the orthogonal sections of the space (Fig. 8). Significantly, in the longitudinal section it is verified that the centres of the hexagons of the nave and the rose window coincide in height. The underlying mesh of equilateral triangles covers the entire floor, configuring plateaus at different levels for different liturgical rituals. 

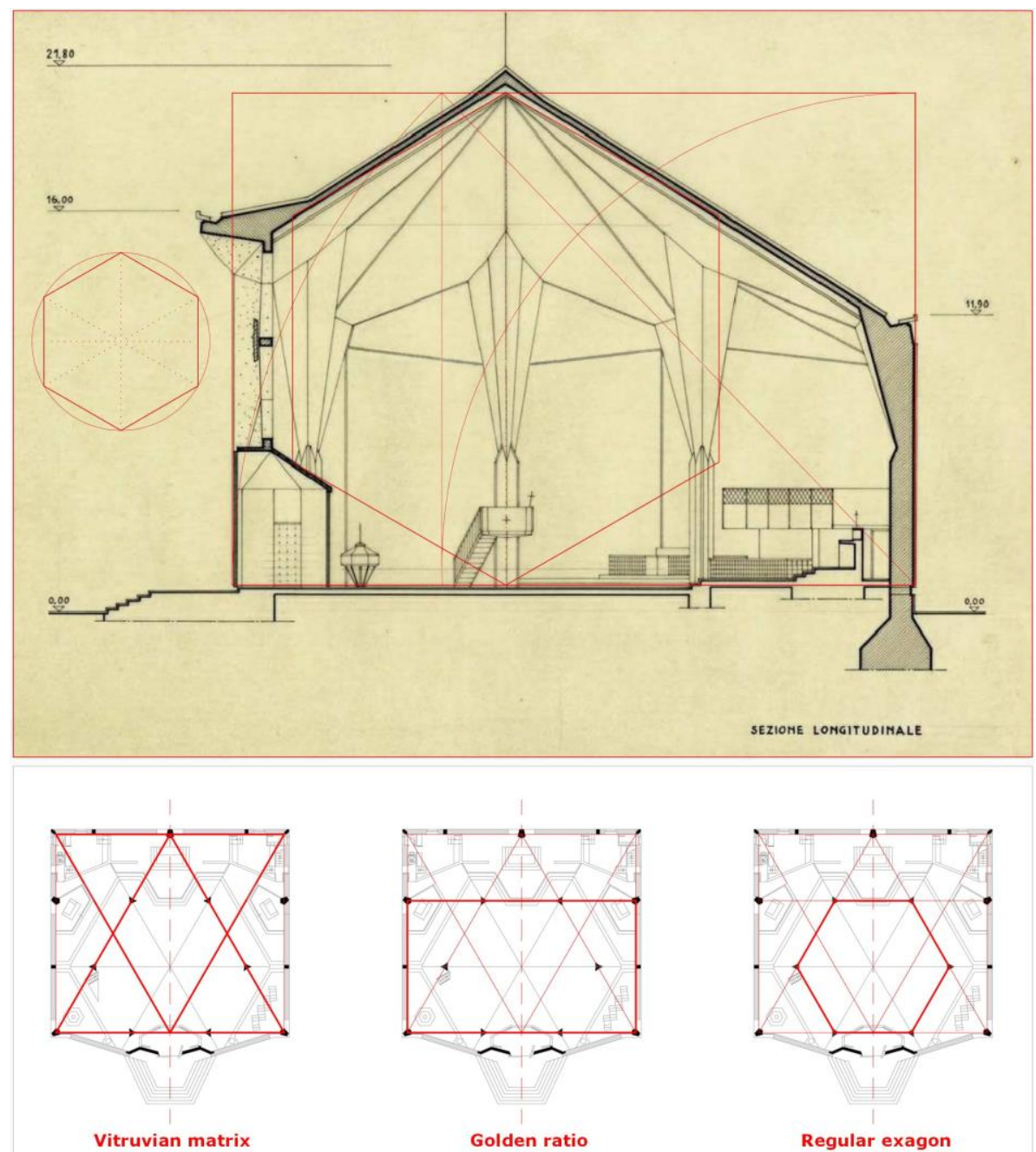

Fig. 8. Church of Cristo Re project (ACS, Archivio Giuliana Genta, 1953-54. Concession n. 1632 / 2021 by permission of the Italian Ministry for Cultural Heritage and Activities. Reproduction or duplication in any form or by any means is prohibited): graphic analysis that allows an identification of the main geometric matrices used to control the drawing of section diagram (top) and the entire planimetric scheme and the drawing of section diagram (bottom)

(Pirinu 2020).

This geometry is applied to the breakdown of the pavement, to the structural pieces (six large triangular section pillars) and to the building's furniture. It is a process of geometric control of all the elements that intervene in the sacral enclosure through careful design, subject to a law that harmonises them, achieving a greater formal, spatial and visual unity where everything finds its correspondence: the cusp of the church is also fixed with the golden proportions of the plant (Fig. 8). The church of 
Cristo Re, like many other works of modern religious architecture, did not ignore history, but made use of it, prolonging its traditions of control of proportions.

\section{Genesis of the 'Sacro Cuore' church project}

The church, promoted by the Figlie di Cristo Re, initially baptised with the name of the 'Sacro Cuore', according to the plans, is implanted next to the two buildings (the social public and the accommodation for the nuns) that the congregation began to build from 1948 in the vicinity of Monte Urpino (an area of expansion of the city of Cagliari), behind the Palace of Justice (1933-38) and near the residential complex in the vicinity of via Pessina designed by A. Libera (ca. 1950). Thanks to the donation of these lands, owned by Baroness Manca di Villahermosa, to the nuns (very active in helping needy families), it was possible to start the institute and residence, and to commission the project of the temple to the engineer G. Maxia, brother of the founding mother. Some time after the laying of the first stone of the convent on January 1, 1950, the project was entrusted to the new technicians Giuliana Genta and Silvano Panzarasa in July 1952 (ACS 1952).

The place where the temple would be erected was slightly elevated by the orography and fell to a square in front of it next to the intersection of two functional roads, a square that would be suppressed with the future. The first project that the architects drew up, in just ten days from July 19 to 28 (ACS 1983), shaped the church as an isolated monolith with its western façade presiding over the traffic artery, separating itself from the adjacent monastic institution and linking both solids by means of a slender bell tower, which served as a hinge and was set back to the rear so as not to detract from the temple itself. This was defined by the perimeter wall that followed the quadrangular plan $(28.30 \times 24.80 \mathrm{~m})$, from which a broken plane advances, generating a convex fold out of the façade — where the door is located-, understood as a push produced by the expansion of the sacral space, a somewhat baroque beat. Mircea Eliade emphasises that every sacred space is a closed space that has an entrance that guides us to its interior, which is, in turn, a new exterior (Eliade 2015).

This closing wall delimits a prismatic volume whose interior — which has a plane of symmetry that joins the door and the altar - is made up of a diaphanous and isotropic space at eye level sliding between the grid of equilateral triangles that starts from the central hexagon. The vertices of this mesh intersect with the perimeter and mark the points where the other five pilasters are housed with to support the unifying roof; These supports interrupt the enveloping wall flanked by vertical floor-to-ceiling windows: the supporting skeleton, therefore, reveals itself to be the protagonist of the interior when it peers outside: a modern gesture of structural sincerity. In this way, within the opaque and traditional volume of the wall, a transparent and modern void explodes, illuminated thanks to these initially triangular rips, which distinguish the role of the concrete skeleton (whose uniqueness is linked to some works by Brazilian Artigas) that, in the folded planes (very similar to those in the Medalla de la Virgen Milagrosa church by F. Candela), it is ribbed and incorporates ceramic vaults that are hidden under a layer of plaster. 
This project for the Sacro Cuore church was presented with two roofing solutions of different heights in order for the Commissione Centrale di Arte Sacra (CCAS) to choose the most suitable one; in both, the freestanding bell tower was fixed, making, at the same time as a hinge, to mark claim in the distance with its square plan and slenderness of a 1:5 proportion, in accordance with Italica custom. The first proposal was for a low wall, a support base for the pyramidal roof with a star plan and a broken profile topped with a lantern (Fig. 9a), which is explored with freehand sketches. A second proposal opted for a double-height wall from which the multiple planes of the 'starry dome' started (Fig. 9b), pointing to the sky without breaks and without a lantern, exceeding $20 \mathrm{~m}$. This cover, supported by a structure of beams that open like the framework of an umbrella (articulated in the meeting with the columns), is what gives a strong unity to the space of the assembly and speaks to the city (Figs. 4b, 1).
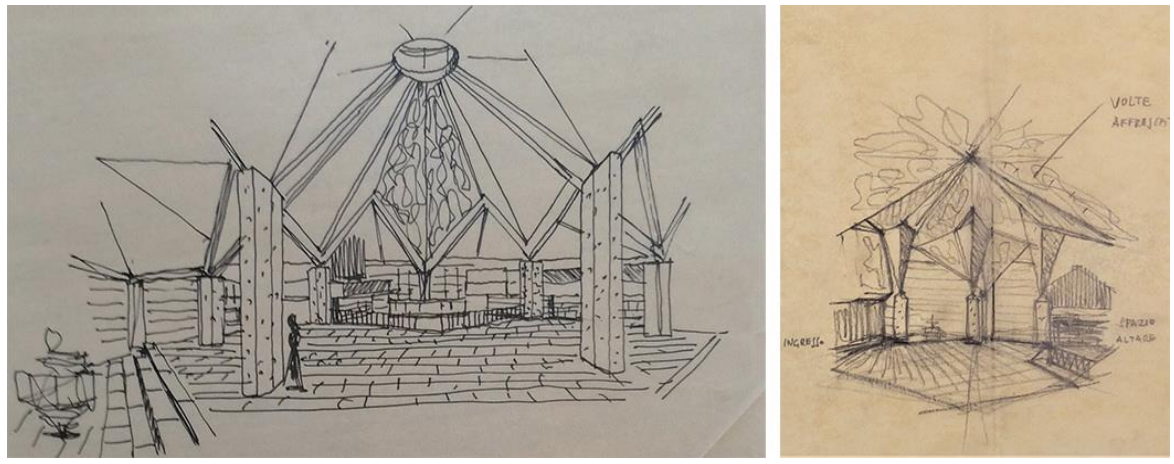

Fig. 9. Preliminary sketches of the interior of Cristo Re, testing solutions for the structure. (a): Columns and straight beams. (b): Columns and laminar beams (ACS, Archivio Giuliana Genta, 1952. Concession n.1632 / 2021 by permission of the Italian Ministry for Cultural Heritage and Activities. Reproduction or duplication in any form or by any means is prohibited).

This faceted dome has different ancestry. A vague reflection could be discovered of the churches of their professor Quaroni, but the most direct source was the project drawn up by the couple for the international Calvert House competition in Canada in the early 1950s, where each of the sloping folds is supported by radially arranged beams, linking with the media discourse of organic architecture, not exempt from a certain expressionist halo. Another fairly direct influence, not only on the roof, but on the columns and pilasters that raise it, comes from the project for the Casmez exhibition Pavilion, the work of A. Libera and G. Girardet, which was completed in 1953 (Fassio 2009, pp. 74-81) and that presents the supporting pilasters converted into trapezoidal planes and that Genta and Panzarasa take up in their columns divided into two sections: triangular base and beams in continuation of the supports opening like ribs. This second option would be the one chosen and the one that would be executed, not without the introduction of some changes in the execution project. It should be noted that the elevations of these two proposals and the ad hoc urban perspectives show the wall as a solid basement with the superposition of courses of stones, passing the matter seen to the foreground, in opposition to the abstraction of pioneering mo- 
dernity. The exterior view (Fig. 10) shows the rusticity of the facing and draws a procession towards the portal; Both popular issues are dealt with in the contemporary projects of Michelucci (Fondazione 2002) and modern architecture hybridises with vernacular and with society: the vertical exterior silhouette and the height of its interior space constituted past reminiscences that were nuanced and stylised to suit the new times. Furthermore, the designers, avid draftsmen, always place human figures in the elevations and in the various conics in order to show the scale of the public architecture.

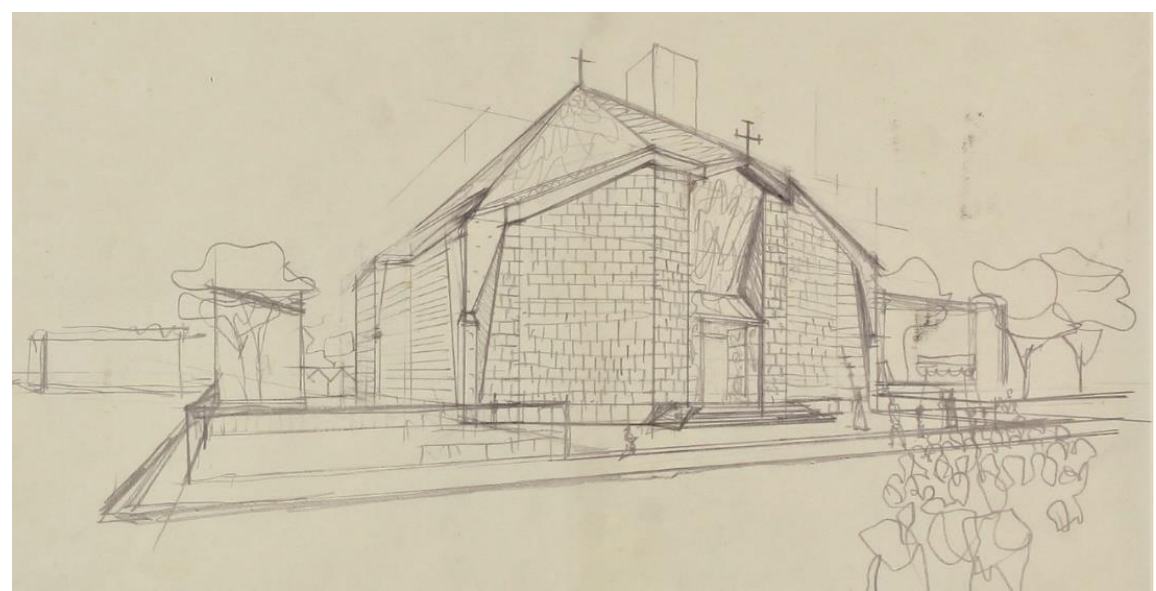

Fig. 10. Perspective of the exterior of Cristo Re church (ACS, Archivio Giuliana Genta, 1952. Concession n.1632 / 2021 by permission of the Italian Ministry for Cultural Heritage and Activities. Reproduction or duplication in any form or by any means is prohibited).

The plan describes a fluid space — crossed only by the six central columns - that bring together the different areas of worship. On the axis of symmetry (culminating in the altar with a Christ of the Sacro Cuore, the work of the sculptor Eugenio de Courten) the assembly is located occupying the hexagon with the benches, in the Baroque manner. Five areas with other liturgical uses surround the central room entered between the wall pilasters. As one advances, and symmetrically, the areas for the sacraments of baptism and confession appear at the same elevation as the nave; next, the two smaller altars on somewhat elevated plateaus and, in the background, the main altar that presents its sacrificial table with its back turned to the nave, as was usual. On both sides of this there are two stores that act as a sacristy on which the choir and the gallery are arranged. Outside, to access the entrance, you go up a staircase that resolves the existing change in level.

This sacred space, together with the permanence of historical constants, provides innovations such as the integration of baptism and the chapels in the unitary interior under the starry dome. Meanwhile, from the city, the church is perceived as a separate world, closed, with the expressionist imprint of an opaque but well-carved gem that, inside, unfolds an unexpected fluid space, illuminated by a diffuse amethyst light that enters through the stained glass windows giving the interior a particular atmosphere 
that emphasizes the slight folds of the ceiling highlighted by the large beams (ACS 1996) and leaves the room in darkness creating the propitious place for the personal communication of the believers with the 'heart' of God. The concrete structure, in its geometric authenticity and material containment, is also visible, finished off with a discreet bush hammer that further reveals its material.

The basic project thus defined, after the approval of the CCAS in August 1952, begins its transformation into the execution project that would guide the works. The project still is for the 'Sacro Cuore'. A church with a hexagonal heart in plan, which reverberates in the sections of the columns, rises up to the star-shaped dome of King David, extends in the exploded view of the pavement, is repeated on the access staircase, it would be applied on the cover itself and it would be moved to the rose window that would illuminate the nave. The architects had probably not read The Library of Babel (La Biblioteca de Babel, 1941) by J.L. Borges, where a law of hexagonal geometry governed the design of that singular piece -"The universe (which others call the Library)"- repeating a pattern that was applied to each part of its architecture.

\section{Execution of the work: the church of Cristo Re}

In memory of the architecture project, the authors summarize the characteristics of the temple stating that entering the church from the wooden atrium you will access a single internal environment in which the pillars, the sacristies with the overlying tribunes, the altars, the baptistery and the confessionals distributed on different heights, will create multiple perspective interests without compromising the unity of the internal environment as it is reported outside (ACS 1953-54). The project, therefore, was quite advanced and defined (Fig. 11). The works had begun in mid-1953 with the excavation and the foundation, in parallel with the drafting of the execution project, which was adapting to changing conditions: to economic resources, to project errors, to the necessity to develop constructive details. On site, following the works, engineers G. Maxia and A. Mulas would follow in quick succession.

In 1954, the architects prepared a model to show to the clients, benefactors and the congregation to raise funds (Tagliacollo 2005, p. 36). This prototype anticipates the final state of the church and three aspects are specified in it. First: on the entrance door, the initial bas-relief is replaced by a large hexagonal rose window with reinforced concrete nerves, an idea and shape suggested by Libera (Tagliacollo 2005, p. 40). Second: the perimeter wall — actually already 'the walls', because the closing wall is decomposed into several sections interrupted by the pilasters that reach the facades - changes its apparent rusticity for a careful design of stone slabs rotating on square pieces (rough inside and diamond pointed outside), forming these planes as large constructed canvases (Fig. 12). And third: the stained glass windows that accompany the five pilasters are designed as straight tears, offering the keys for the interpretation of the interior sacrum under the dome. At the instigation of Gio Ponti, photos of the model were sent to Editorial Domus in order to participate in the Mostra Triennale in Milan that year (Capolino 2008, p. 37). In some plans, undated, already appears the title "Nuova Chiesa di Christo Re, Cagliari" (New church of Cristo Re, 
Cagliari) (ACS 1953-54). The two architects think and project the entire interior with details in perspective (Fig. 14).
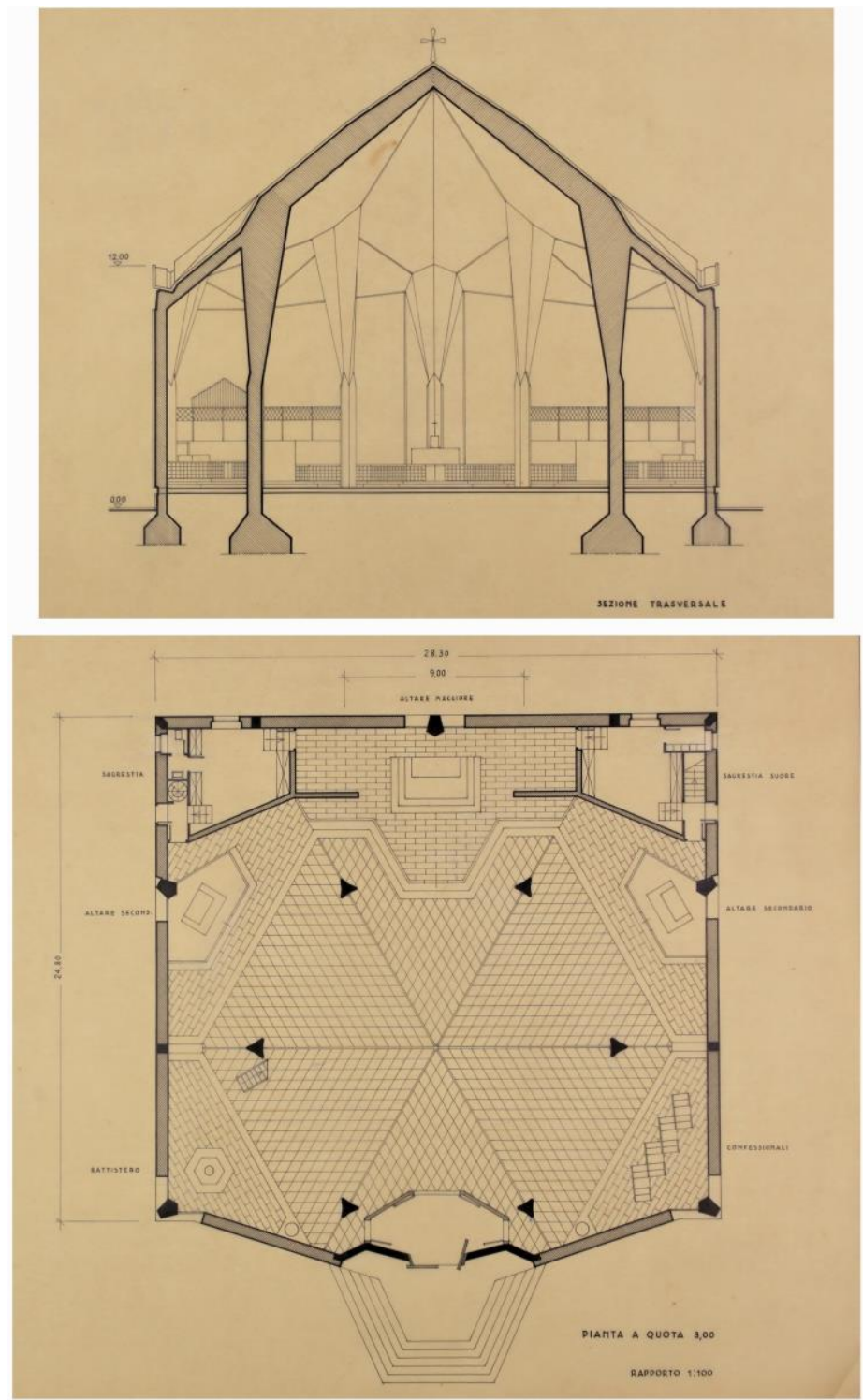

Fig.11. Project for the Cristo Re church, Cagliari, Genta \& Panzarasa (ACS, Archivio Giuliana Genta, 1953-54. Concession n.1632 / 2021 by permission of the Italian Ministry for Cultural Heritage and Activities. Reproduction or duplication in any form or by any means is prohibited). (Top): Cross section through the center of the dome.

(Botton): Ground floor (height $+3.00 \mathrm{~m})$. 


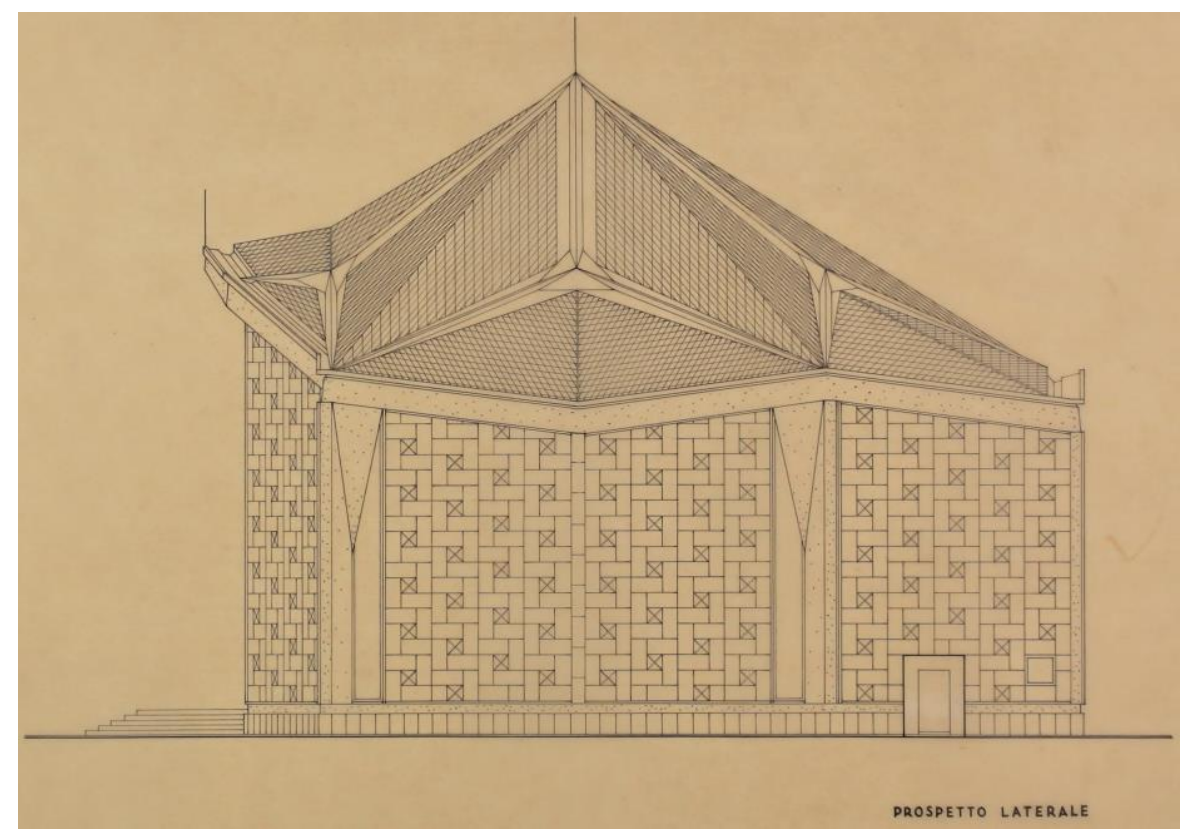

Fig. 12. Project for the Cristo Re church, Cagliari: South side elevation (ACS, Archivio Giuliana Genta, 1953-54. Concession n.1632 / 2021 by permission of the Italian Ministry for Cultural Heritage and Activities. Reproduction or duplication in any form or by any means is prohibited).

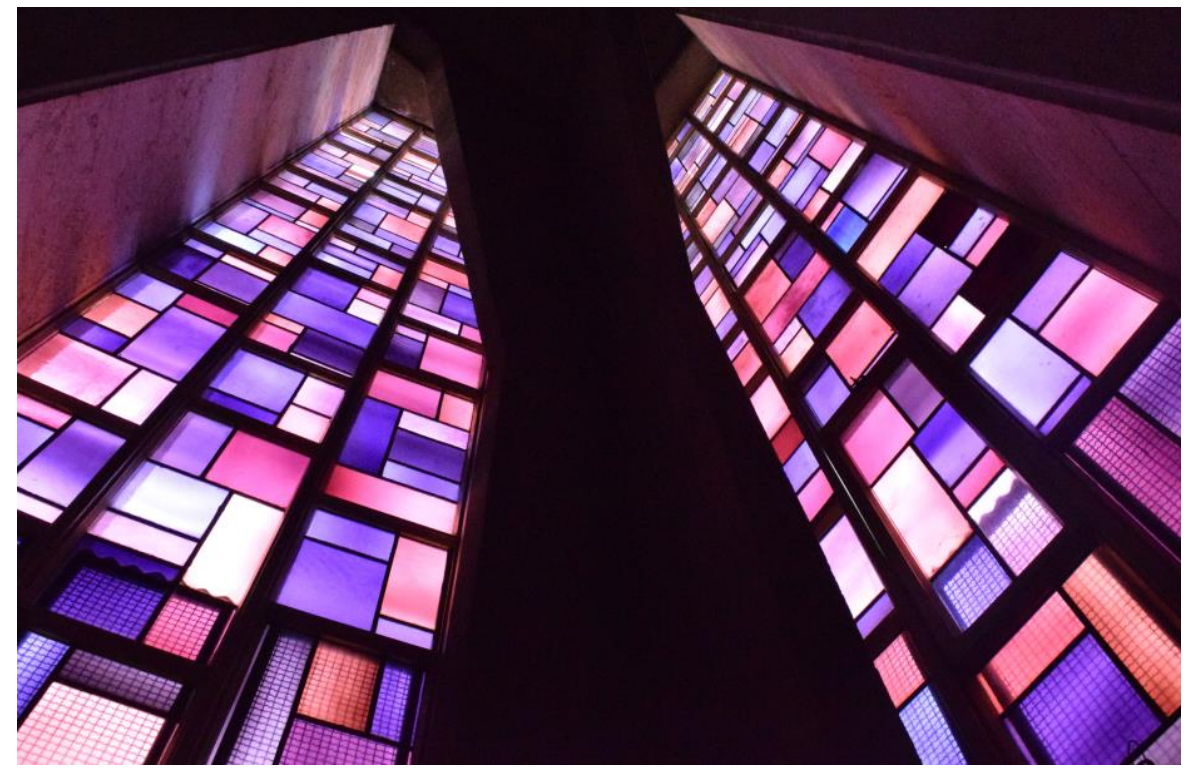

Fig. 13. View from the inside of the pair of stained glass next to a corner pilaster (Authors 2020). 
Between 1955 and 1957, the aerial structure was calculated by the engineer Viettone and Marta, moment in which the new radial structure of the beams that support the star-shaped dome appears, but its execution is slow. In 1958, the church is now closed in by the folded star, allowing the appreciation of the impact of the concrete dome, under which some masses are celebrated that summer. Then the finishes begin, which requires new details. The concrete rose window is replaced by another with golden aluminum profiles and the windows are specified with the same materials (Fig. 13): translucent cathedral glass tiles, in a range of tones that varies from violet to purple, for which are drawn new plans dated November 1958 (Fig. 15) (ACS).

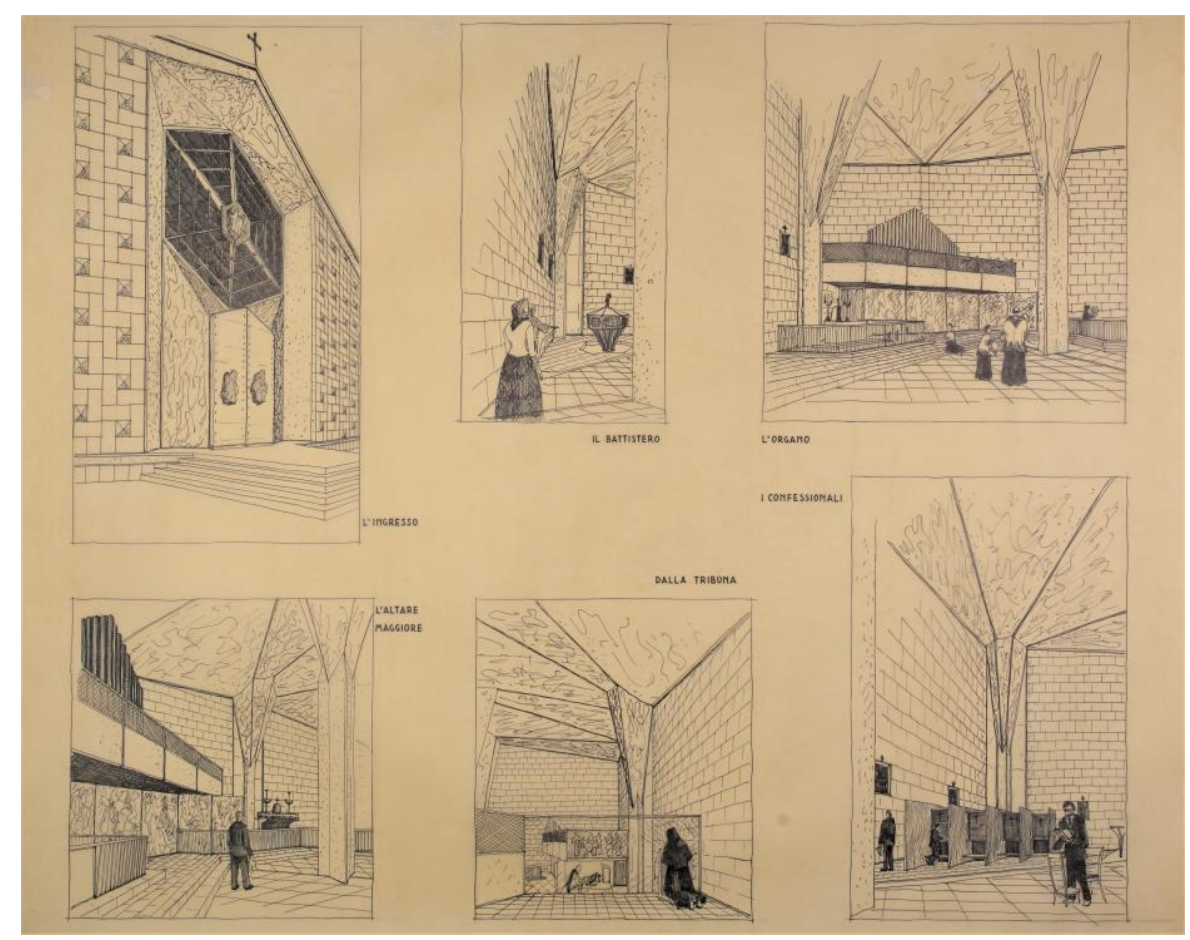

Fig. 14. Perspectives: view of the entrance and five views of the interior: baptistery, choir, altar, nave and confessional (ACS, Archivio Giuliana Genta, 1953-54. Concession n.1632 / 2021 by permission of the Italian Ministry for Cultural Heritage and Activities. Reproduction or duplication in any form or by any means is prohibited).

The interior finishes require a prior study of these environments, which is why several perspectives are drawn that recreate them: the entrance itself, the baptistery, the organ, the altar, the rostrum and the confessionals, providing multiple plans that detail the masonry cutting schedules of the stone walls, the aluminum lattices or the benches. Some of these elements are executed throughout 1959. Perhaps it has not yet been sufficiently emphasised, but the architects elaborate an enormous quantity of preparatory and complementary graphic documents (sketches, hand drawings, plans, details, perspectives, etc.) during the whole of the project and construction process. 


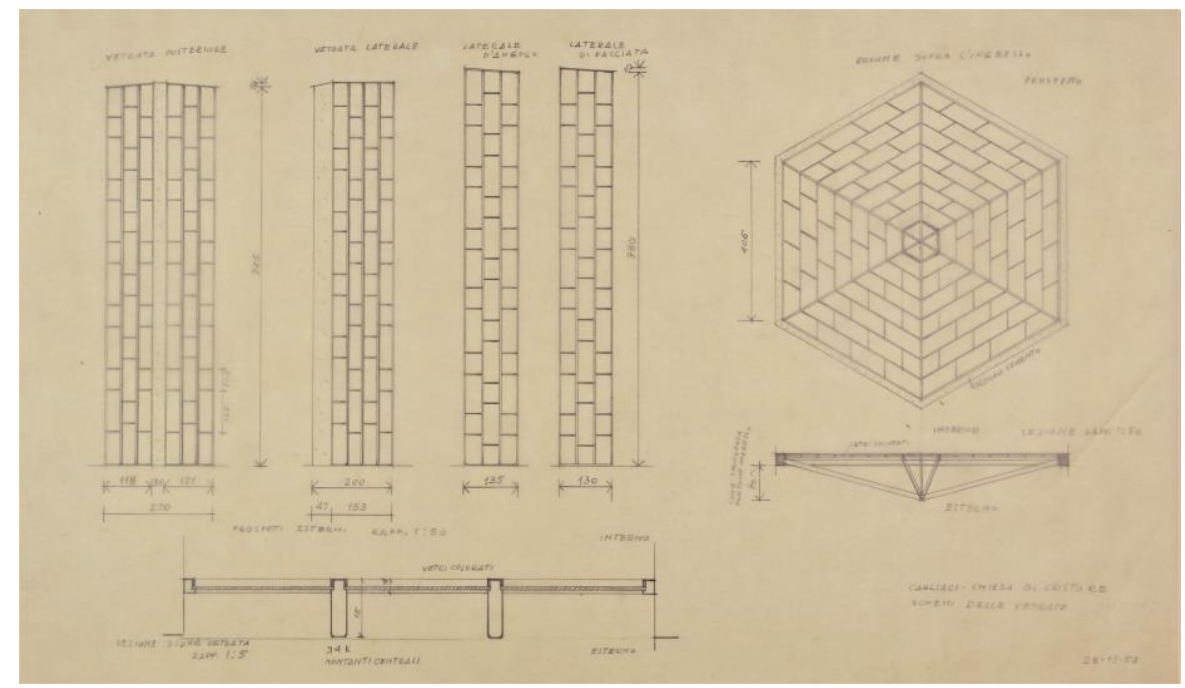

Fig. 15. Design of the vertical stained glass and the hexagonal window (ACS, Archivio Giuliana Genta, Nov 28, 1958. Concession n.1632 / 2021 by permission of the Italian Ministry for Cultural Heritage and Activities. Reproduction or duplication in any form or by any means is prohibited).

The following year, 1960, the roof was covered with glazed ceramics - which remains within the constructive traditions of the Mediterranean, in particular of Sardinia - and the design and execution of the main altar, the tabernacle and the exterior finishing cross were carried out. Then came the secondary altars, the lattices, the furniture ... resolved with exquisite care in their geometric settings and selection of materials in line with the design of the church itself. However, the soffit of the 'star dome' would not be painted, ending up simply plastered. The three years that remained until its inauguration were spent finishing the last finishes (bronze gate, marble flooring and altars, stained glass windows...) as the difficulties were solved (Fig. 16). Finally, the church was consecrated on September 21, 1963 after eleven years of dedication, although Giuliana Genta's relationship with the church, now Cristo Re, would last throughout her life, attending to the requests of the congregation, including the grave of Mother Bruna herself (Capolino 2008, pp. 38-39). 


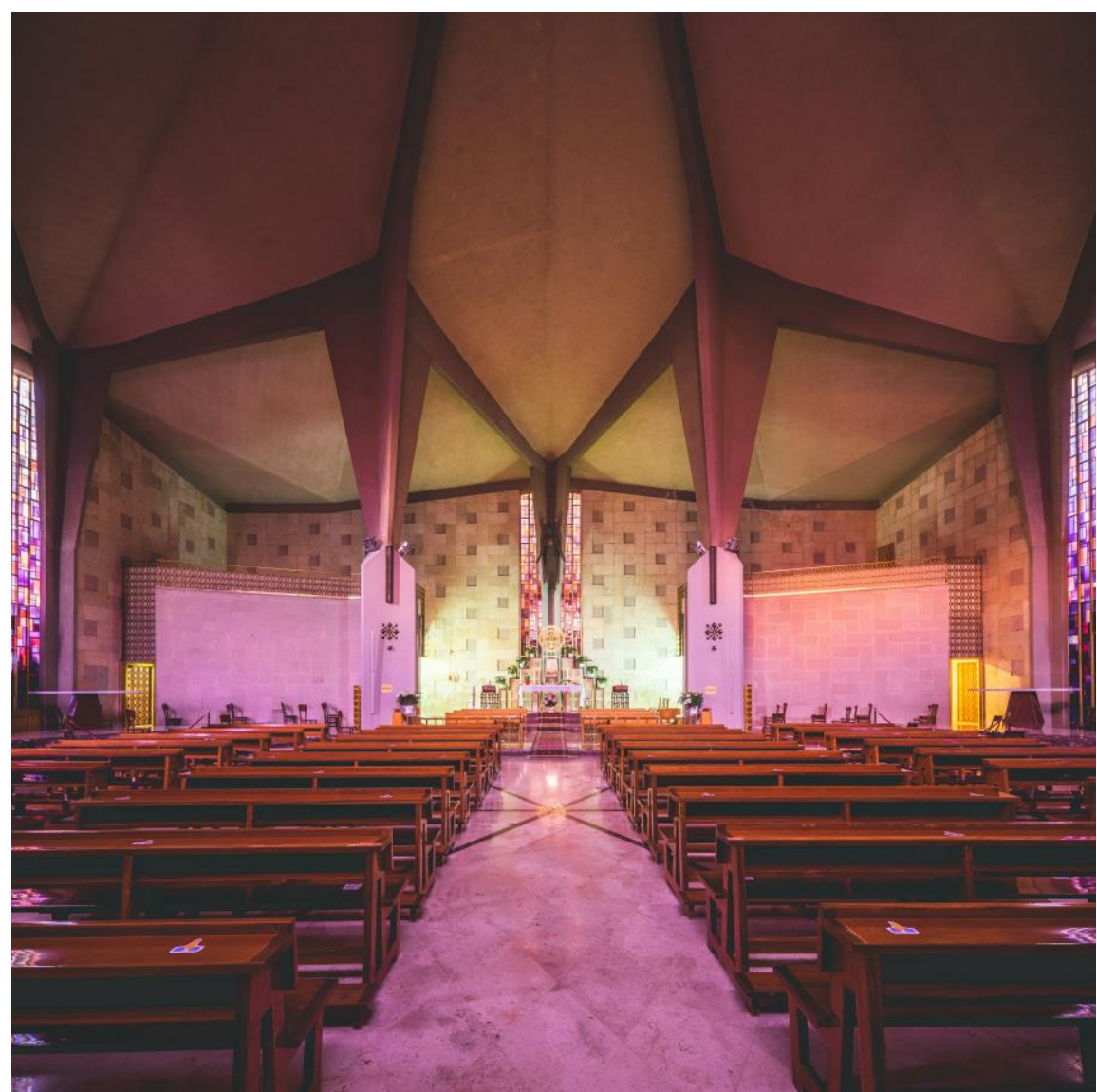

Fig. 16. Interior of Cristo Re: view of the sacral interior with the paneled pavement, the main altar and the star dome, with purple light from stained glass reflecting off material surfaces; On the altar, in the center of the perspective, stands the sculpture of Cristo del Sacro Cuore

(N. Paba 2020).

\section{Between tradition \& modernity: closed exterior, open interior}

From an urban point of view, for the second post-war period in Italy, churches continue to be crucial in residential neighbourhoods, public buildings, presiding over a public square, isolated by their role and highlighted by their volumes. The church of Cristo Re meets these requirements of urban location, independence as a building and differentiated and unique profile of the temple and its bell tower; the latter adjusted to the Italian historical tradition of stylised visual landmark (without fanfare) that, over time, will lose prominence because residential buildings equal it in height, diminishing its contribution to the Cagliari skyline. However, the church does stand as a reference for the neighbourhood. 
Significantly, this church, without intending to, maintains an ancestral premise: its canonical orientation to the east. But, perhaps it is the permanence of older symbolisms that allows us to understand it as a sacred place: discreetly elevated and conceived as a volume that, from the outside, is hermetic thanks to the limit of the solid stone wall with a single access that leads us to its sacred heart: an expanded interior that is covered, not with a spherical dome, but with a starry cover. Orientation, closure and metaphor of heaven, in very subtle ways, are established and live in the church of 'Cristo Re', initially of the 'Sacro Cuore'.

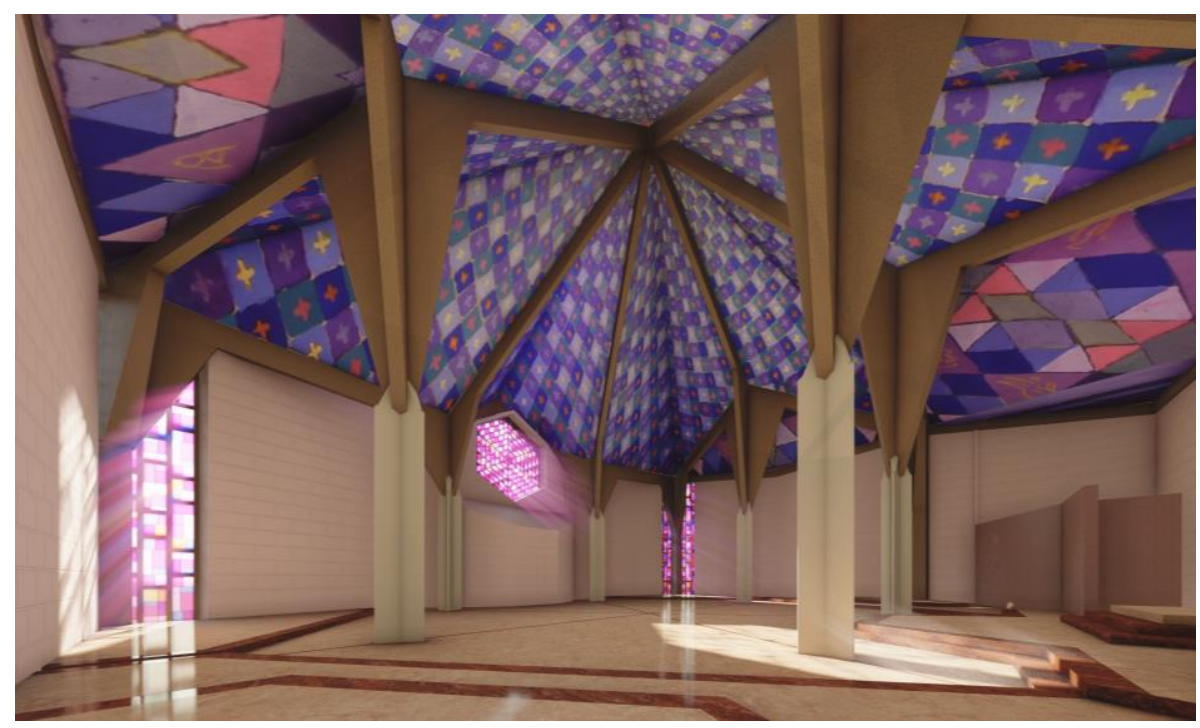

Fig. 17. Interior of Cristo Re: 3D recreation of the sacred space of the church with the design of the sky of the dome: Night (J.M. Moreno 2020).

As we have already described, the project echoes the new currents of modern architecture, although it distances itself from the formal dogmatic axioms of the modern movement. Undoubtedly, by opting for a reinforced concrete skeleton that remains visible, both inside the enclosure and outside in the envelope, allows experimentation with a decidedly modern isotropic void that renews the historic compartmentalised religious space and, in this sense, this architecture shows certain ancestry in the baroque where the different spatial areas interact with each other and are juxtaposed: the interior expands and its drive agitates the dynamic but serious plane of the western façade. The authors, who have learned the lessons of modernity (Genta 2005), add to their achievements (structural independence and spatial transparency) the materiality of the finishes and the immateriality of the symbolisms. These have been possible from a geometry, ancient and demanding, that assumes the friendly face of the new organic architecture that emerges with media force in the middle of the century.

In fact, the new hexagonal meshes as a reference to articulate the sacral spaces in plan would have a fortune in the sixties. They would illustrate this renewed typological family, to cite some significant cases: the contemporary church of the Nuoro pris- 
on (1953, M. Ridolfi), and the later San Pier Damiano church in Ravenna (1955-64, G. Gandolfi), Sagrados Corazones parish in Madrid (1961-65, R. García-Pablos whose dedication reverberates in the initial of 'Cristo Re'-), San Policarpo church in Rome (1964-67, G. Nicoloso —of an exquisite workmanship_-), as regards the Catholic world, and, for the multi-denominational roofless church Chapel in New Harmony (1960, P. Johnson — which already opens new symbolic and liturgical horizons-). But if there is a church that we have to mention again, it is that of the Medaglia Miracolosa (1953-69, A. Verri), here, in Cagliari, which uses the hexagon as a modul, but whose entrance is located at the vertex as in the Madrid case. It is evident that the isometric mesh also responds to a rational geometry, if anything, more flexible and adaptable to the most varied requirements and, of course, capable of generating fluid and diaphanous spaces as in Cristo Re church.

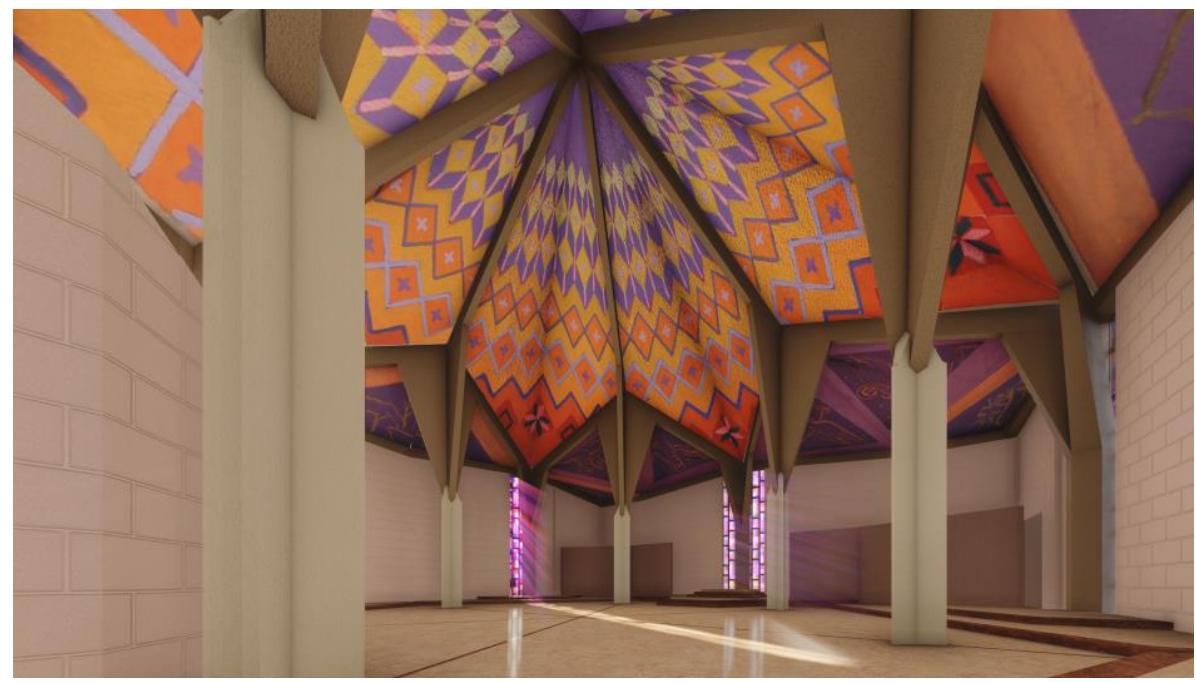

Fig. 18. Interior of Cristo Re: 3D recreation of the sacred space of the church with the design of the sky of the dome: Day (J.M. Moreno 2020).

To conclude, it is important to highlight this way of organic experimentation hybridised with certain historical architectural constants that are updated. The use of the central plan for the assembly of parishioners, the axis of symmetry of the access to the altar and scrolling this out of the dome, the discret verticality of the space determined by the plant's golden ratio, the dome reinterpreted in a folded star (Figs. 17, 18), the composition from the golden ratio plots, the materiality and its vernaculars textures as a principle, and the use of the free-standing bell tower and slender confirm these teachings of History that remain in modern sacred architecture and that feed on tradition. Perhaps it is necessary recalling the words of K. Popper on the subject: "Tradition is - apart from innate knowledge - by far the most important source of our knowledge" (Popper 2003, p. 73). So we can read the church of Cristo Re in Cagliari, of Genta e Panzarasa, as a good example of this hybridisation between the novel contributions of the modern movement and those that are distilled from the tradition it- 
self, with roots in the Baroque period. As the authors them-selves state when they draw and explain their first 1952 project proposal, inside the central space is hexagonal, wide-ranging, completed all around by altimetrically different spaces. The roof of the Church, that rises from the hexagonal space, impresses the whole environment with an ascensional force (ACS 1952). A work whose conception is modern, but whose appearance and spirit take root in the Classical world, in the traditions of the Mediterranean.

\section{References}

1.Aa.Vv.: Adalberto Libera. Opera completa. Electa, Milano (2001).

2.ACS (Archivio Centrale dello Stato, Giuliana Genta). Documentation consisting of various projects, details, sketches, reports, photographs and letters; many of these are undated, most from 1952 to 1963; "Relazioni" (Memories) of 1952, 1953-54, 1983-ca. and 1996.

3.Bettazzi, M.B.; Gresleri, G.; Gresleri: CH+Q 1955-1968. Chiesa e Quartiere. Storia di una rivista e di un movimento per l'architettura a Bologna. Editrice Compositori, Bologna, 2004.

4.Capolino, P., Tagliacollo, E.; Diodovich, L.: Giuliana Genta: la mia vita da architetto. Prospettive, Roma (2008).

5.Conforto, C.; De Giorgi, G.; Muntoni, A.; Pazzaglini, M.: Il dibattito architettonico in Italia, 1945-1975. Bulzioni Editore, Roma (1977).

6.Della Longa, G.: La Arquitectura Religiosa contemporánea en Italia y la experiencia de la Conferencia Episcopal Italiana en su promoción. AARC, 1 (1), 106-129 (2007).

7.Eliade, M.: Lo sagrado y lo profano. Espasa Libros, Barcelona (2015).

8.Fassio, A.: Il padiglione espositivo Casmez a Cagliari (A. Libera, G. Girardet, 1953). In: Bardelli, P.G.; Cottone, A.; Nuti, F.; Poretti, S.; Sanna, A.: La costruzione dell'architettura. Temi ed opere del dopoguerra italiano. Gangemi Editore, Roma (2009).

9.Fernández Arenas, A.: Iglesias nuevas en España. Ediciones La Polígrafa SA, Barcelona (1963).

10.Fondazione Giovanni Michelucci (ed.): Giovanni Michelucci. Disegni 1935-1964. Diabassis: Reggio Emilia (2002).

11.Gabinetto dei Disegni-Castello Sforzesco: Ambito romano, Pianta di chiesa esagonale (Inv. SM 1, 11). Milano (1600-1640).

12.Genta, G.: Una lezione di progettazione di Giuliana Genta. AR, XL (62), 44-45 (2005).

13.Gherardi, L.; Giordani, P.L.; Lullini, L.; Trebbi, G. (eds.): Dieci anni di architettura sacra in italia, 1945-1955. Edizione dell'Ufficio Tecnico Organizzativo Arcivescovile, Bologna (1956).

14.Gil, P.: El templo del siglo XX. Barcelona: Gustavo Gili, Barcelona (1999).

15.Hitchock, H.R.; Johnson, P.: El Estilo Internacional. Arquitectura desde 1922. COAATM, Madrid (1984).

16.Johnson, P.: Creadores. Ediciones B, Barcelona (2008).

17.Kidder Smith, G.E.: Nuove Chiese in Europa. Milano: Edizioni di Comunità, Milano (1964).

18.Loddo, G.: Guida all'architettura contemporanea di Cagliari 1945-1995. Coedisar, Cagliari (1996).

19.Loddo, G.: Il Padiglione Casmez di Adalberto Libera alla Fierra di Cagliari. CUEC Editrice, Cagliari (2001). 
20.Longhi, A.: Storie di Chiese. Storie d Comunità. Progetti, cantieri, architetture. Gangemi Editore, Roma (2017).

21.Longhi, A.; Tosco, C.: Architettura, Chiesa e Società in Italia (1948-1978). Edizioni Studium, Roma (2010).

22.Meduri, G.: Quarant'anni di Architetura Sacra in Italia, 1900-1940. Le questioni, il dibattito, le polemiche. Gangemi Editore, Roma (2016).

23.Pichard, J.: Les Églises nouvelles à travers le monde. Éditions des Deux-Mondes, Paris (1960).

24.Piseddu, A.: Le chiese di Cagliari. Zonza Editori, Cagliari (2000).

25.Popper, K.: En busca de un mundo mejor. Barcelona: Paidós, Barcelona (2003).

26.Sanna, A., La chiesa e il convento di S. Domenico a Cagliari (R. Fagnoni, E. Bianchini, 1949-1954). In: Bardelli, P.G.; Cottone, A.; Nuti, F.; Poretti, S.; Sanna, A.: La costruzione dell'architettura. Temi ed opere del dopoguerra italiano. Gangemi Editore, Roma (2009).

27.Tagliacollo, E.; Capolino, P.: Giuliana Genta: imparare con Libera. Controspazio, XXXV, (116), 36-41 (2005).

Vidler, A.: Historias del presente inmediato. La invención del movimiento moderno arquitectónico. Gustavo Gili, Barcelona (2011).

\section{Acknowledgments}

To the architect Nicola Paba for the photographs of the churches of Cagliari and that of Cristo Re, as well as the photomontages made for this occasion. To the architect José María Moreno for the 3D modeling of the interior of the Cristo Re church with the two solutions of the painted ceiling. 